\title{
Turkish Parents, Teachers, and Faculty Members' Opinions and Experiences on Safety Skills Instruction for Children with Autism Spectrum Disorder
}

\author{
Elif Tekin-Iftar",a, Nursinem Sirin ${ }^{b}$, Belva C. Collins ${ }^{\circ}$
}

$\begin{array}{ll}\text { Received } & : \text { 23 June } 2020 \\ \text { Revised } & : \text { 26 November } 2020 \\ \text { Accepted } & : \text { 28 December } 2020 \\ \text { DOI } & : \text { 10.26822/iejee.2021.197 }\end{array}$

This study was supported by a Grant from Anadolu University Research Fund (Project No: 1304E070).

Correspondance Details: Elif Tekin Iftar Anadolu University, Research Institute For Individuals With Disabilities, Eskisehir, Turkey.

E-mail: eltekin@anadolu.edu.tr

ORCID: http://orcid.org/0000-0001-5512-616X

${ }^{b}$ Nursinem Sirin

Anadolu University, Eskisehir, Turkey.

E-mail: nrsnm_nrsnm@hotmail.com

ORCID: https://orcid.org/0000-0001-8421-1937

- Belva C. Collins

University of North Carolina Charlotte, Department of Special Education and Child Development, Charlotte, USA.

E-mail: belva.collins@uncc.edu

ORCID: https://orcid.org/0000-0002-4011-8471

\begin{abstract}
Although sometimes neglected, safety skills instruction should be considered as important a teaching area as others (e.g., self-care, academic, communication skills) because these skills can lead to more independence in a less restrictive environment. The researchers designed this study to reveal the opinions of Turkish parents, teachers, and higher education faculty members regarding safety skills instruction for children with an autism spectrum disorder. They interviewed parents ( $n=11)$, special education teachers ( $n=16)$, and higher education faculty members $(n=11)$ and analyzed the resulting data descriptively. Findings showed both parents and teachers lacked information about safety skills and how to teach them. Higher education faculty members advised using evidence-based practices in teaching safety skills and stated that safety skills instruction was not covered in the special education teacher training curriculum in the programs in which they taught. Implications and future research needs are discussed.
\end{abstract}

\section{Keywords:}

Autism Spectrum Disorder, Safety Skills, Parent Opinions; Teacher Opinions, Higher Education Faculty Member Opinions

\section{Introduction}

A utism spectrum disorder (ASD) is a complex disability Acharacterized by social communication and interaction impairments accompanied by repetitive behaviors, and restrictive interests and activities (American Psychiatric Association, 2013). Although prevalence estimates vary, there is agreement that the number of individuals diagnosed with ASD has been rising steadily (e.g., Christensen et al., 2016; Kogan et al., 2009). This rising rate places huge demands on health, education, and social systems of the countries since children with ASD require appropriate education and care to become more independent. Therefore, considerable research and educational effort have focused on providing evidence-based practices (EBPs) for teaching children with ASD.

Safety skills (SS) instruction is often neglected but is important for everyone. Research has shown that safety risks are common among all children regardless of having a disability. Each year, many children face the risk of injury or death and 


\section{iejee $\approx$}

physical or sexual abuse (e.g., Bergstrom, Najdowski, \& Tarbox, 2012; Clees \& Gast, 1994; Dixon, Bergstorm, Smith, \& Tarbox, 2010; Istre, McCoy, Carlin, \& McClain, 2002). Researchers have reported that children with ASD and other developmental disabilities have two to three times the risk of injury or abuse compared with their same age peers without disabilities (e.g., Agran \& Krump, 2010; Calavari \& Romanczyk, 2012; Volkmar \& Wiesner, 2009), and the mortality rate of individuals with ASD is more than double that of those without disabilities (Chavelle, Strauss, \& Picket, 2001). Although there are no studies on the risk rates in Turkey, it can be assumed that the need for safety skill instruction is the same.

A major goal of education is to prepare children with ASD to become more independent; however, increased independence may increase safety risks and the need to teach SS (Clees \& Gast, 1994). High priority should be given to providing SS instruction to children with $A S D$, yet relatively few studies have focused on SS instruction as compared to other skill areas. Existing SS studies have focused on teaching children with ASD to seek help when lost (e.g., Bergstrom et al., 2012; Taylor, Hughes, Richard, Hoch, \& Coello, 2004), use mobile phones to obtain assistance when lost (e.g., Hoch, Taylor, \& Rodriguez, 2009), respond to the lures of strangers (e.g., Akmanoglu \& Tekin-Iftar, 2011; Bergstrom, Najdowski, \& Tarbox, 2014; Gunby, Carr, \& LeBlanc, 2010; Gunby \& Rapp, 2014), use safe pedestrian skills (e.g., Harriage, Blair, \& Miltenberger, 2016), apply first-aid skills following home accidents (e.g., Ergenekon, 2012), acquire general and body SS (e.g., Kenny, Bennett, Dougery, \& Steele, 2013), and use household SS (e.g., Degirmenci \& TekinIftar, 2019; Summers et al., 2011). Relatively recent two meta-analysis studies identified SS interventions that have demonstrated promising evidence for use with individuals with ASD based on single-case research studies (Tekin-Iftar, Olcay-Gul, Sirin, Bilmez, Degirmenci, \& Collins, 2021; Wiseman, McArdell, Bottini, \& Gillis, 2017). Both studies concluded that more research is needed.

Although acquisition of SS is important for survival, teaching these skills is usually not a high priority in educational systems. For example, the current curriculum offered to $\mathrm{K}-12$ students with $\mathrm{ASD}$ in Turkey includes only a few SS objectives under the independent living domain, such as self-protection, personal health, and safely navigating roads designed for pedestrians (Milli Egitim Bakanligi, 2013). Teaching SS to children with ASD has gained the attention of the researchers in Turkey in recent years, but they have conducted only a few studies investigating teaching various SS to the children with ASD to date (Akmanoglu \& Tekin-Iftar, 2011; Degirmenci \& TekinIftar, 2019; Ergenekon, 2012; Kurt \& Kutlu, 2019). Studies have indicated that children with ASD need direct and explicit training instruction on SS, from basic domestic skills to social SS, with an emphasis on maintenance and generalization (Summers et al., 2011; Volkmar \& Wiesner 2009).

Parents, teachers, and higher education faculty members play important roles in educational planning and programming for children with ASD in schools. Although parents and teachers are directly involved in the education of children with ASD, faculty members are indirectly involved by providing input for school curricula for children with ASD, providing effective and efficient research-based strategies to teach SS to children with ASD, providing advocacy for educating children with ASD to become independent members of society, and training teacher candidates and/or related personnel who will teach/work with children with ASD. Even though promising practices are documented in the research for teaching SS to children with ASD (e.g., Akmanoglu \& Tekin-Iftar, 2011; Bergstrom et al., 2012), these skills may be neglected by parents and teachers (Sirin \& Tekin-Iftar, 2016).

The fact that children with ASD and other developmental disabilities have a greater risk of injury or abuse than their peers without disabilities and that SS instruction is a neglected instructional area provided the impetus to examine the opinions of parents, teachers, and faculty members regarding SS instruction for children with ASD. This study explored the opinions of Turkish parents and teachers of students with ASD and of faculty members who teach in a graduate program in Applied Behavior Analysis (ABA) regarding SS instruction. The researchers addressed the following questions: (1) What are the experiences of parents and teachers in teaching SS to their children/students with ASD?, (2) If they had experience teaching SS to children/students, what skills have they taught and what types of difficulty have they experienced while teaching them?, (3) If they did not have experience teaching SS but would like to teach them, what kind of knowledge and skills do they think they need?, (4) What are the opinions and suggestions of teachers about the instructional procedures used during SS instruction?, (5) What are the opinions and suggestions of faculty members regarding who should teach SS to children with ASD?, (6) What are the opinions and suggestions of faculty members about the instructional procedures to be used during SS instruction?, and (7) What are the opinions of faculty members regarding an undergraduate program on special education covering SS content and how to teach these skills to children with ASD?

\section{Method}

\section{Participants}

As a type of purposive sampling, the researchers used typical case sampling in the study. That is, they 
selected parents, teachers, and higher education faculty members (hereafter shortened to faculty members) based on their representation as typical or average members of the selected affected population. The researchers conducted the study with 11 parents (10 mothers, 1 father), 16 special education teachers ( 12 females, 4 males), and 11 faculty members (9 females, 2 males) in an urban area in a mid-size province (population $=883,000$ ) of $13,925 \mathrm{~km}^{2}$ in central Turkey.

Inclusion criterion for the parents was having children with ASD attending a special school for students with ASD on a full-time basis. The 11 parents who participated in the study ranged in age from 23 to 40 years (mean $=33.81$ ). Two parents were between 20 30 years old range and the remaining parents were in between 31 - 40 years old range. The majority held high school diplomas, and only three were employed. It is important to note that the mothers described themselves as "housewives," which is a traditional gender role of women in Turkey. In addition, due to lack of caregiving and special education services available to children with special needs, it is not unusual for one of the parents (typically the mother) of a child with a disability to choose to stay at home as a caregiver of a child with a disability. While eight mothers were unemployed, two were state officers, and a father was a police officer. The researchers did not collect data on socioeconomic status. While six parents held high school degrees, three held upper secondary degrees and two held college degrees. The ages of the parents' children ranged from $4-10$ years $(M=$ 6.72), and nine of the 11 children were male. Eight of the children had atypical autism, and three had autism diagnoses. Eight of the children attended a university unit to receive special education services, and three attended special education schools for children with ASD and intellectual disability. Five students received language and speech therapy and support services during the study, and three participated in inclusive settings. In Turkey, children whose functioning is most affected by the severity of their autism are placed in special schools, as was the case with these children. The ages of the 16 special education teachers who participated in the study ranged from $24-47$ years ( $M$ = 34.18). Seven teachers were between 20 - 30 years old range, five were between 31 - 40 years old range, and the remaining teachers were at or older than 41. Each held a bachelor's degree in special education, and had $1-23$ years of teaching experience. Ten teachers had 1 - 10 years of teaching experience, four teachers had 11 - 20 years of teaching experience, and two teachers had more than 20 years of teaching experience. The special education teachers were employed in a university unit or special school designed to provide special education services to children with ASD and other developmental disabilities; 12 worked at special schools with the remainder employed at a university unit. Both the university unit and special school were segregated settings. The university unit, housed at a Research Institute for children with developmental disabilities, provided special education services to preschool-aged children with developmental disabilities. Children attended this unit five days per week on half-day basis. Only three children of the participating families also attended half-day inclusive day-care. The special school served students with ASD between the ages of $7-15$ years.

The 11 faculty members (nine females and two males) who participated in the study ranged in age from 35 51 years $(M=40.72)$ and had $12-24$ years of teaching experience. The faculty members were professors teaching courses in the first and only graduate program in ABA in Turkey and conducting research on teaching children with ASD. Four faculty members had conducted research on teaching children with ASD; the rest taught children with intellectual disability or provided professional development for special education teachers during their doctoral dissertations.

\section{Instruments and Data Collection}

The first and second researchers prepared interview questions based on the SS instruction literature for children with ASD, as well as other developmental disabilities (e.g., Agran \& Krump, 2010; Agran, Krump, Spooner, \& Traice-Lynn, 2012; Collins et al., 1991; Ivey, 2004). They sent data collection instruments electronically to five experts holding doctorates in special education who had extensive teaching experience with (a) working with parents of children with ASD, (b) teaching children with ASD, and (c) qualitative research methods and/or interview methods. They grammatically revised several questions. The data collection instrument had two group of questions: (a) Demographic Questions and (b) SS Questions. The researchers asked the following SS questions while interviewing parents and teachers.

1. Have you ever taught any SS to your children? If "yes," How did you teach SS to your children?

2. What were the easiest parts of this instruction?

3. What kind of difficulties have you had during this instruction? If "no," If you were going to teach SS to your children, what kind of knowledge and skills do you need to have?"

4. What do you think and suggest about instructional procedures used during SS instruction? (teachers only).

The researchers asked the following questions while interviewing faculty members.

1. Who should provide SS instruction to children with ASD?

2. What do you think and suggest about the instructional procedures used during SS instruction? 


\section{iejee}

3. What do you think about whether special education teacher training programs include SS instruction and what topics are included regarding SS?

Prior to study, the researchers obtained approval from university review board. The steps followed for data collection included conducting pilot interviews, developing an interview guide, adopting interview principles, and conducting interviews. The first two researchers developed the interview guide to determine the order of the questions, the extent to which details would be given for each question, expectations of interviewees, how to record interviews, how to terminate an interview session, and how to give information about the researcher to those being interviewed prior to the interviews. The second researcher then conducted and recorded initial pilot interviews. Including the first researcher, the experts teaching graduate level courses on interview methods listened to the recordings; they then provided coaching for the second researcher to actively listen and raise new questions prompted by the interviewee's responses. Based on their feedback, the second researcher conducted three more interviews. The same experts listened to these recorded interviews and did not suggest or recommend any other changes.

The second researcher contacted the administration from both the special education school and the university unit, and the director of graduate program to make an appointment. At each appointment, she introduced herself; explained the purpose of the study; inquired about the number of eligible teachers, parents, and faculty members to participate in the study; and expressed her intention to visit both school locations and the university to select teacher, parent, and faculty members volunteer to participate in the study. After obtaining addresses of potential participants, she scheduled meetings with them. In the meetings, she explained the purpose of the study and finalized who would participate. She informed participants about the confidentiality of recorded conversations (with the exception of the reliability coder). The second researcher provided each participant with the written informed consent and requested that the signed informed consent form be returned to her. The second researcher conducted a total of 11 parent interviews in the university unit's classroom, Rehabilitation Center's Special Education classroom, or parent's waiting room of the special school. She also conducted a total of 16 teacher interviews - four interviews in the same university unit classroom where the parents had been interviewed and 12 in the classroom in the special school for children with ASD where the teachers worked. In addition, she conducted a total of 11 interviews with faculty members in their offices. The researcher and the participant were the only ones present during the interviews in these settings.
She conducted all interviews in Turkish, the native language of all participants; they lasted between 3 to $12 \mathrm{~min}$. The researcher audio taped each interview as well as took and kept daily notes in a journal prior to interviews and/or after interviews about the content of the interviews and/or participants.

\section{Design}

The researchers used descriptive analysis of the interview data. Descriptive studies are designed to describe the situation at the time the research is conducted (Cresswell, 2005).

\section{Data Analysis}

Using a separate form for each participant's interview, the second researcher transcribed data verbatim. The researchers used descriptive analyses with the following steps: (a) transcribe data, (b) have a graduate student check interview transcriptions, (c) form categories based on responses of participants, (d) categorize choices into categories, (e) develop interview coding keys based on the responses of participants, (f) have two independent experts code data separately, (g) calculate reliability coefficients for each question using number of agreements divided by number of agreements + disagreements $\times 100$, (h) conduct a reliability analysis on interview coding keys, and (i) descriptively analyze themes. The researchers obtained a mean reliability agreement of 90\% (range $=75-100 \%$ ) on parent interviews, 93\% (range $=80-$ 100\%) on teacher interviews, and 95\% (range $=75-$ $100 \%$ ) on faculty interviews. In preparing the results for dissemination, the first author translated the quotes into English and, as a native speaker, the third author checked these quotes; then, the first author checked them once more to increase accuracy.

\section{Results}

\section{Parents/Teacher Experiences in Teaching Safety Skills to Children/Students with ASD}

Table 1 shows parent/teacher experiences in teaching SS and which SS they have taught to their children/ students with ASD. Of 11 parents, six reported they had taught SS and four reported they had never taught SS to their children. One parent did not know. Parents who had not taught SS said their children could learn these skills when needed $(n=2)$ and they take necessary precautions to protect their children $(n=2)$.

Ten teachers reported they had not systematically provided SS instruction to their students with ASD, whereas six teachers reported they had systematically provided SS instruction for at least one skill. Three teachers indicated they had provided SS instruction to their students with intellectual disability in the past. 
Table 1

Parents' and Teachers' Experiences Teaching Safety Skills

\begin{tabular}{lrlr}
\hline Parent Responses & $n$ & Teacher Responses & $n$ \\
\hline Yes & Have you ever taught safety skills to your children/students? & 10 \\
\hline No & 6 & I have not taught systematically & \\
\hline I do not know & 4 & I have taught systematically & \\
\hline Total & 1 & I have taught systematically to students with intellectual disability & 3 \\
\hline \multicolumn{1}{c}{ What safety skills have you taught to your children/students? } & 19 \\
\hline Staying away from hot stove & 11 & Total & \\
\hline Using scissors safely & 3 & Using stairs safely & \\
\hline Not touching power outlets & 2 & Using scissors safely & 1 \\
\hline Staying away from home chemicals & 2 & Staying away from lighter, matches & 1 \\
\hline Staying away from sharp objects & 2 & Staying safe in roads & 1 \\
\hline Protecting against physical violence & 2 & Wearing weather appropriate clothes & 1 \\
\hline Staying away from kitchen sink & 2 & Using traffic lights & 1 \\
\hline Sitting safely in car & 1 & Crossing street safely & 1 \\
\hline Using knife & 1 & Staying away from dangerous objects & 1 \\
\hline Total & 1 & Using fork & \\
\hline
\end{tabular}

The teachers who had never provided SS instruction said that they had warned students $(n=2)$, had warned parents $(n=1)$, had provided instruction at the moment students needed to learn a specific SS $(n=1)$, or had taken precautions in the classroom ( $n=$ 1). Teacher three, who had not provided SS instruction, indicated the reason by explaining priorities:

If we think, the first skill area to work with students with ASD would be communication; then comes self-care skills. After that, depending on the students performance levels, other skill areas could be studied. Teaching serious SS are being considered at a later stage.

Teacher 11 said she did not take students to work on SS in real settings but tried to teach those skills when they were out: "We did not go out to work on specific Ss; however, when we went out for another reason and there was a danger, then I occasionally tried to teach skills necessary for him/her to protect himself/ herself there." Teacher 16 said that her students did not initiate anything to put them in danger: "I did not feel a need to teach these skills in the school since my students did not initiate anything dangerous. I believe their parents have taught these skills to them."

Safety Skills Taught by Parents/Teachers and Difficulties They Have Experienced

Table 1 shows SS taught to children and students with ASD by parents and teachers who said that they had taught them. Parents had taught staying away from hot stove $(n=3)$, using scissors safely $(n=2)$, not touching power outlets $(n=2)$, staying away from home chemicals $(n=2)$, staying away from sharp objects $(n=2)$, protecting against physical violence $(n=2)$, staying away from kitchen sink $(n=1)$, sittings safely in car $(n=1)$, and using a knife $(n=1)$. When asked how they taught these skills, two mothers stated they verbally described how to perform the SS. For example, Mother One stated, "He used to open windows or doors when I am taking him somewhere in my car. I always told him not to open the windows or doors. He is not doing that anymore." Two mothers said they performed the SS themselves and asked their children to imitate. Mother Two said:

My child was bringing scissors too close to his eyes. My husband and I taped the edges of the scissors not to hurt him - don't know we did the right thing -... Then, I held the same scissors without the tapes. I wanted him to imitate me as I showed him how to cut. We took off the tape. Then, he began to cut. First, he couldn't hold it. We helped him hold.

Mother Three, one of two mothers that taught these skills spontaneously in the daily routine, said:

...at home, especially the knives in the kitchen are easily accessible for him. We taught him that they are dangerous. I showed it on myself. I mean, I accidently cut my hand while preparing salad and he saw me. I said, 'Look, it hurts; the same may happen to you. I mean, you will not touch the knives; they may hurt you. We are not touching the knives.

The researchers asked parents who taught SS to explain the difficulties they faced while teaching them. Two mothers said they had difficulty when they used verbal direction. On the other hand, they also said their children had learned appropriate SS when faced with danger. Mother Three said: 


\section{iejee $\sqrt{2}$}

We experienced difficulties. No matter how well his receptive language, he sometimes could not get what was told to him. He needed to experience it. I tried to verbally explain to him the problems, but he could not get them. He had to experience to understand that it was dangerous to him.

As can be seen in Table 1, teachers have taught using stairs safely $(n=3)$, using scissors safely $(n=2)$, staying away from lighters and matches $(n=1)$, staying safe in roads $(n=1)$, wearing weather-appropriate clothes $(n=1)$, using traffic lights $(n=1)$, crossing street safely ( $n$ $=1$ ), staying away from dangerous objects $(n=1)$, and using forks safely $(n=1)$. When the researchers asked teachers $(n=7)$ to explain how they taught these skills, they said they used various materials and teaching strategies that included using picture cards $(n=3)$, modeling ( $n=2)$, asking questions and/or asking child to perform safety behaviors ( $n=2)$, using dramatization $(n=1)$, reading stories about safety $(n=1)$, videomodelling $(n=1)$, using a task analysis $(n=1)$, watching cartoons with students about safety $(n=1)$, and using direct instruction ( $n=1)$. Teacher Three said, "I took my students to a parking area in the schoolyard; then, we walked around the cars. I turned on the car and had them walk around in order to make the setting as much the same as a real traffic setting." Teacher Five explained, "We had to work on traffic lights; however, school administration did not allow us to take the students to the streets. Therefore, I had to use picture cards and found some cartoons to watch about traffic lights together."

The researchers also asked teachers who taught SS to explain difficulties they experienced while teaching. They had problems in individualizing instruction $(n=2)$, securing students' attention in real settings $(n=1)$, not being able to conduct SS instruction in real settings where skills are needed $(n=1)$, establishing control at beginning of instruction $(n=1)$, and organizing instructional settings $(n=1)$. One teacher said that she had not had any problems during SS instruction. Teacher Five said:

Model and demonstrate is not enough to teach SS. I am sure there must be some other strategies. Students with ASD have their own routine, and you cannot change it. If you can change it, then come problem behaviors. As a result, I better say I go easy on them.

\section{Parents/Teachers Who Did Not Have Experience Teaching Safety Skills - If They Would Like to Teach Them and What Kind of Knowledge and Skills They Think They Need}

The researchers asked parents and teachers what kind of knowledge and skills they need if they would like to teach SS to their children and students with ASD. (See responses in Table 2) Parents reported they were not well-versed in teaching SS to their children and needed support from experts. Mother Two stressed the need to get support from teachers before initiating
SS training, saying, "I don't know; of course, I need support from the teacher. I mean, if I can learn the right methods from the teacher, for sure I will be more helpful for my child. I need to learn the methods from them in order to apply them with my child." Mother Eight said support should continue during SS training as well:

...I should ask for the comments and feelings of the teacher. Or I can ask to prepare the task analysis together, or, for instance, where do I make mistakes? I can ask her to watch me or make a video recording. I sure will make mistakes somewhere... For example, during the training, I can ask her to observe...

In addition, Mother Nine stated that she may need information and skills regarding how she should interact with her child during SS training:

The way that I will talk with my child; I mean, in our daily lives, we talk with them, but it would be better if we learn something more detailed from teachers. I mean, we raise them as normal parents do. But, of course, it will be better to get instruction from experts... Of course, it will be better for us if we can enhance our experiences by learning from the experts...

Mother Six stated she could get information regarding precautions but not about how to teach SS:

For example, how should we do it? I mean, I was wondering when my child was a baby. I mean, sometimes children can swallow small objects. I searched from the Internet. But it is not on the web, how can I teach them... For example, there are things that I can do for myself, but nothing about training my child."

Teachers stated they needed to know how to teach SS and which strategy to use. At the same time, they explained they needed to know needs and performances of their students regarding SS. (See Table 2) Teacher Nine stressed the need for published materials about SS instruction:

When you ask about teaching SS, I need to stop and think since SS are higher order skills for the students as well as for me. I hardly introduce them myself to my students; I do not know how to teach these skills. If I have a book guiding me in this area, I would be very happy.

Teacher 11 also indicated a need:

Indeed, teaching strategies. Actually, we learned many teaching strategies during our college education; when it comes to implementing them in the schools, I could not implement them systematically. We have a crowded classroom, too many students and too many objectives to teach. We need a kind of guidebook explaining to us practically how to teach these skills. Such as which skills could be taught with which strategy. How does learning occur easily?

Teacher 15 stressed the importance of having a guidebook on how to provide SS instruction:

Teachers need to be encouraged. We were required to teach preventive skills to these students, but if we would think to teach them to become more independent, then teaching SS would be more 


\section{Table 2}

Knowledge and Skills Parents and Teachers Think They Need to Have and Teacher Recommendations for Strategies for Safety Skills Instruction

\begin{tabular}{|c|c|c|c|}
\hline Parent Responses & $n$ & Teacher Responses & $\mathrm{n}$ \\
\hline Teacher and expert support & 7 & Teaching strategies & 6 \\
\hline Need to know how to teach & 5 & Experts to consult & 3 \\
\hline Special education and skills & 2 & Information about student's performance and needs & 3 \\
\hline Basic safety information & 2 & Task analyses of skills & 2 \\
\hline Task analyses of skills & 1 & Training materials & 2 \\
\hline \multirow[t]{7}{*}{ Communication skills } & 1 & Handbook about teaching safety skills & 2 \\
\hline & & Information about which skills to teach and why to teach & 1 \\
\hline & & Opinions of family members & 1 \\
\hline & & Educational programs & 1 \\
\hline & & Information about characteristics of student & 1 \\
\hline & & Effective teaching strategies & 1 \\
\hline & & Information on how to assess in real setting & 1 \\
\hline Total & 18 & & 24 \\
\hline \multicolumn{3}{|c|}{ Teacher responses about recommendations for strategies } & $\mathrm{n}$ \\
\hline \multicolumn{3}{|l|}{ Video modeling } & 5 \\
\hline \multicolumn{3}{|l|}{ Model and Perform } & 3 \\
\hline \multicolumn{3}{|c|}{ Errorless teaching (e.g., graduated guidance, most-to-least prompting) } & 3 \\
\hline \multicolumn{3}{|c|}{ Can be identified based on student } & 3 \\
\hline \multicolumn{3}{|l|}{ Can be identified based on skill } & 2 \\
\hline \multicolumn{3}{|c|}{ Can be identified based on student and skill } & 2 \\
\hline \multicolumn{3}{|l|}{ Modeling } & 2 \\
\hline \multicolumn{3}{|l|}{ Dramatization } & 2 \\
\hline \multicolumn{3}{|l|}{ Applied methods } & 2 \\
\hline \multicolumn{3}{|l|}{ Providing real-life experience } & 2 \\
\hline \multicolumn{3}{|l|}{ Peer tutoring } & 1 \\
\hline \multicolumn{3}{|l|}{ Pictorial methods } & 1 \\
\hline \multicolumn{3}{|l|}{ Total } & 28 \\
\hline
\end{tabular}

important. For this reason, we need to have some guidebook and published materials. Teaching SS includes many risks. While preparing training materials, these risks should be considered seriously.

Teacher 12 stated SS instruction is similar to teaching any skill in other domains:

First I would assess the student. I would identify what SS he/she has and what he/she needs to learn. Then, I would prepare/design materials. I would also discuss this with parents and plan where to teach this skill. Then, the rest of it comes by itself. It is not more difficult than teaching a skill in any domain, such as self-care.

\section{Teacher Opinions/Suggestions about Safety Skills Instructional Procedures}

Table 2 also shows teachers' responses about instructional procedures to be used during SS instruction. Teachers reported they could use video modeling $(n=5)$, modeling and performing $(n=3)$, errorless teaching $(n=3)$, modeling $(n=2)$, dramatization $(n=2)$, applied methods $(n=2)$, real life experiences $(n=2)$, peer tutoring $(n=1)$, and pictorial methods $(n=1)$ when teaching SS. They also stated the instructional procedure would be appropriate for student characteristics $(n=3)$, type of skill $(n=2)$, and both student characteristics and type skill $(n=2)$. Teacher seven said, "Video modeling is very important for me, many people learn from TV. I use visual strategies as much as I can." Teacher 15 said, "Errorless teaching procedures can be used. Sometimes one or two procedures could be used together. For example, video modeling and graduated guidance."

\section{Faculty Member Opinions/Suggestions About Who Should Teach Safety Skills}

Table 3 shows faculty members' opinions about who should teach SS. They reported that anyone in the family $(n=6)$ or teachers and parents $(n=3)$ could deliver SS instruction to children with ASD. Faculty Four said, "We have findings that teaching strategies can be used effectively by others. So, I am thinking that 
SS can be taught by non-professional people, too;" and Faculty Five stressed that SS instruction could be delivered by different people, depending on a child's developmental stage:

Since teaching these skills should be started at very early ages, people who - like mother, father, siblings, and primary caregivers - the child is most frequently with - could deliver instruction. It should be started like this. Early childhood teachers should start teaching these skills systematically. In the subsequent years, when the social interactions of a child increases, peers could also deliver SS instruction to them.

As shown in Table 3, three faculty members reported teachers and parents should teach these skills. They advised that, since SS instruction requires systematic teaching, teachers should provide guidance to parents and peers. Faculty Two said, "These skills should be taught in the schools during the acquisition phase; then, after providing parent training, parents can start to work on these skills to promote generalization." On the other hand, two faculty members indicated the nature of the SS would determine the instructor. For example, Faculty Four said, "...while teaching personal SS, such as teaching private parts of the body, teaching to distinguish strangers, and teaching to distinguish inappropriate touching, privacy is essential. Therefore, it may not be suitable to use peers when teaching such a skill."

\section{Table 3}

Faculty Members' Opinions on the Delivery of Safety Skills Instruction

\begin{tabular}{|c|c|}
\hline Faculty Members Responses & $n$ \\
\hline \multicolumn{2}{|c|}{ Who should deliver SS instruction to students with ASD? } \\
\hline Anyone in student's life (e.g., mother, father, siblings, close relatives, peers) & 6 \\
\hline Teachers and parents & 3 \\
\hline Change depend upon safety skill to be taught & 2 \\
\hline Teachers and experts & 1 \\
\hline Total & 12 \\
\hline \multicolumn{2}{|c|}{ Which procedures should be used during SS instruction? } \\
\hline Evidence-based practices & 5 \\
\hline Can be decided according to characteristics of student and skill & 5 \\
\hline Visual strategies & 5 \\
\hline Systematic teaching procedures & 3 \\
\hline Errorless teaching procedures & 3 \\
\hline Naturalistic teaching procedures & 1 \\
\hline Social stories & 1 \\
\hline Total & 23 \\
\hline \multicolumn{2}{|c|}{ Do special education undergraduate programs include content about SS instruction? } \\
\hline Only little in some courses & 4 \\
\hline I do not know & 3 \\
\hline I talk about safety skills instruction in my courses & 3 \\
\hline Not enough & 2 \\
\hline No (as far as I know) & 2 \\
\hline Total & 14 \\
\hline
\end{tabular}

\section{Faculty Member Opinions/Suggestions About} Instructional Procedures

The researchers asked faculty members which instructional procedures should be used during SS instruction. (See Table 3) They stated EBPs $(n=5)$, those identified depending onstudentand skill characteristics $(n=5)$, visual strategies $(n=5)$, systematic teaching procedures $(n=3)$, errorless teaching procedures $(n=$ $3)$, naturalistic teaching procedures $(n=1)$, and social stories $(n=1)$. Among faculty members stating EBPs be used, Faculty four said, "It is not enough to consider the effectiveness of these procedures as it will be affected their parents and surrounding environment; social validity of the procedures should also be considered." Faculty Five indicated the importance of errorless teaching procedures: "The child has no opportunity to make a mistake while using a knife or while learning a SS about knives. Therefore, it is better to use the methods in which we use the most intrusive prompt."

\section{Faculty Member Opinions Regarding Safety Skills and How to Teach Them}

The researchers asked faculty members whether special education programs in Turkey cover teaching SS in courses or in course content. (See Table 3) Faculty members said SS instruction is covered very little in 
some courses $(n=4)$, they do not know $(n=3)$, they personally talk about SS instruction $(n=3)$, there is not enough information $(n=2)$, or it is not covered $(n=2)$. Among those who said SS instruction is covered very little in some courses, Faculty One stated, "I think it is mentioned briefly under self-care and daily living skills training; I know that, under sexual training, there is something; some skills are being taught regarding protecting oneself;" and Faculty Two indicated;

It is mentioned in the context of life sciences, as only one subtitle or skill, but they are not presented as a whole, in a more careful and concentrated manner... In life sciences, there is, for example, appropriate clothing for the seasons or not to drink cold water too fast or not to touch objects with a red cross on it or not to use things with a red drop on it... We work on such subjects, but are they highlighted in the programs? No.

Two faculty members said content for SS instruction is not covered in the special education program. Faculty 11 explained, "There is no subject which directly covers training of SS." Faculty Two reported;

We don't have a subject which is programmed to teach SS in a neat, orderly, catchy manner, without missing any steps. But it is essential for our special education department students to acquire some information and training to teach these skills; however, I do not think that this issue is being dwelt on, as far as I know.

\section{Discussion}

The purpose of this study was to explore the opinions of Turkish parents, teachers, and faculty members regarding SS instruction for children with ASD. Parents and teachers had different experiences, and their opinions showed both similarities and differences. Half of the parents said they have taught SS to their children; however, their examples were usually preventive (e.g., staying away from stove, using stairs safely, using scissors safely). Neither parents nor teachers provided examples for teaching social SS (e.g., children protecting themselves from strangers or from physical and/or sexual abuse) or more complex SS. When the researchers asked parents how they delivered SS instruction to their children, it appeared that, rather than providing instruction, they provided verbal warnings (e.g., Stay away from stove, It is hot, Do not touch, You would get burned) in the presence of any safety risk. This seems to convey that, rather than providing instruction, parents have spontaneously used possible consequences of safety risks as hints for themselves to warn their children not to repeat their behaviors in the presence of safety risks in the future. It appears parents may not be aware of the difference between teaching and warning. For example, when a child touches a hot stove, he/she would be in pain. Due to this punishing consequence, the child may not touch the hot stove in the future, and parents may perceive this as a learning outcome of their warning. Research has established that, unless taught systematically, children with ASD may fail to learn new skills and may fail to generalize when learning occurs (Doyle \& Doyle-lland, 2004; Scheuermann \& Webber, 2002). Therefore, a warning by itself should not be considered teaching; instead, both parents and teachers need to consider providing systematic instruction. In addition, they need to consider not only teaching SS to $100 \%$ criterion but also programming for generalization and maintenance since research has shown children with ASD often have difficulty in performing acquired skills in novel settings or over time. The data also showed the majority of the teachers did not teach any SS. They thought their students were not ready to learn SS, or a few thought SS instruction includes some risks, and, if they exposed students to these risks, parents or school administrators would blame them. For example, Teacher 12 said, "I do not teach riding a bike to my students. Why? If he falls down while practicing it, we would have big problems with parents." These findings showed that teachers are not required to teach SS on a regular basis. In other words, the curricula for teaching students with ASD does not cover SS goals and objectives.

There are similarities between the experiences of parents and teachers in teaching SS to children with ASD. Both parents and teachers who have provided SS instruction taught various preventative skills instead of how to react or protect oneself in the presence of any safety risks. They either warned them (e.g., Stay away from hot stove) to prevent safety risks or took some precautions (e.g., "We do not have safety risks in our classroom."). A wide range of safety risks occur, however, in daily life, and, to become more independent, children with ASD need to learn how to react and protect themselves.

Data were consistent with previous studies regarding the lack of teaching SS (Collins, Wolery, \& Gast, 1992; Collins, Wolery, \& Gast, 1991; Sirin \& Tekin-Iftar, 2016; Wiseman et al., 2017). Therefore, this study adds to the literature by addressing the need for more research in safety skills instruction as suggested by Tekin-Iftar et al. (2021) and Wiseman et al. (2017). The possible reasons for neglecting to teach SS can be explained from two perspectives. First, data showed that neither parents nor teachers felt they were well-equipped to offer SS instruction. It is possible that, if they did not know how to teach these skills, they simply failed to teach them. Second, instead of teaching SS, parents and teachers arranged the environment to protect their children. Although needs to be investigated, as a subjective opinion, the researchers thought that protecting a child from safety risks instead of teaching SS could, in part, come from the Turkish culture. In contrast to a western attitude, parents and teachers in Turkey may tend to be more protective and sometimes perform behaviors on behalf of their children/students. Opinions of teachers and faculty members showed 


\section{iejee}

differences regarding which instructional procedure to use for teaching SS to children with ASD. When asked, teachers thought of more specific procedures, such as video modeling, modeling, or dramatization. Faculty members, however, thought more broadly and talked from a global perspective using more contemporary terms. They suggested using EBPs, systematic teaching, and/or a group of procedures, such as errorless teaching procedures. Only a few teachers and faculty advised identifying instructional procedures based on the characteristics of children and skills and using more than one procedure at a time while teaching SS. The literature has shown behavioral skill training (BST) as one of the wellestablished procedures in teaching SS to children with disabilities (Tekin-Iftar et al., 2021). The steps of BST include (a) exposing children to information - causes of danger, possible safety risks, and how to react in unsafe situation; (b) modeling - how to behave during unsafe situation; (c) providing practice - allowing children to perform model's behaviors; and (d) providing feedback - providing consequences following correct and incorrect behaviors of children (Miltenberger \& Gross, 2011). Gunby et al. (2010) used an effective BST in teaching three children with ASD "to go away by saying no" in response to the lures of strangers. Ergenekon (2012) also successfully used a BST in teaching three children with ASD to use firstaid skills during home accidents. Author and Author (2011) used video modeling and graduated guidance in teaching three children with ASD to respond to the lures of strangers. As these studies show, behavioral training packages can be effective in teaching SS. There was consistency between the participant suggestions in this study and instructional procedures used in research studies.

There were differences in the opinions of faculty members regarding whether special education undergraduate programs should include a course or course content for teacher candidates on how to provide SS instruction. Some said they partially covered this topic in their courses, and some said they did not share any information. When special education programs are reviewed, courses with titles such as "Teaching Daily Living and Social Skills" include several topics (e.g., home safety, consumer safety) related to SS instruction. In other words, comprehensive content (from assessment to teaching) for SS instruction does not exist in the program, but some faculty make an effort to deliver information about SS instruction.

This study showed that SS instruction had not been delivered at homes or in schools by the participants. ASD is a complex developmental disability with two core deficits: (a) difficulty with social interactions and communication and (b) repetitive behaviors, interest, and activities (American Psychiatric Association, 2013). These characteristics increase the likelihood of life-long safety risks. Students with ASD may fail in distinguishing safe and unsafe situations, knowing how to ask for help, and staying away from dangerous situations. Therefore, SS instruction should be delivered in a systematic way from preschool through adulthood. The data, however, revealed that parents and teachers only teach SS occasionally and in an unsystematic way, and they lack knowledge on how to teach SS. Parents have attempted to teach ss but have not been trained to do this systematically with formative data collections to analyze effectiveness. In addition, special education teacher training programs do not cover SS instruction comprehensively. Some teachers may lack the knowledge to use systematic instruction while others may fail to apply their knowledge of systematic instruction to SS. Although the data were limited to Turkey and may not represent a broad range of participants, other countries may experience the same issues; thus, there is a need for other researchers to expand our research to a broader base.

Based on these results, this study contributes to the professional literature on SS instruction in the following ways: (a) adding to the groundwork on the necessity of teaching SS systematically to students and children with ASD (since the findings showed that this has not been the case), (b) providing information regarding the circumstances under which these skills should be taught, (c) reporting data with three different participant groups from Turkey, making some comparisons of opinions across groups possible, and (d) illustrating the gap in special education teacher training programs and the curriculum of students with ASD in terms of safety teaching.

In light of these points, the following suggestions for practice and future research are presented. While this study is limited to a specific country, it suggests that the opinions of parents, teachers, and faculty members should be considered in SS instruction. Other researchers in other countries should use this study as a basis for further exploring this topic. Both parents and teachers should consider becoming more knowledgeable about SS instruction (e.g., which SS to teach with which instructional procedure, the types of skills that are appropriate to teach and needed at various ages, when to teach SS, and how to promote generalization). Teachers should search for professional development and consultations on this topic to better serve their students. In addition, teachers and parents should consider closely working together in teaching SS. The curricula for teaching children with ASD in Turkey should be revised and goals and objectives added for SS instruction in classrooms, with an emphasis on skills that students need to be more independent in inclusive environments. Faculty members may consider having more content about SS instruction in special education teacher training programs. This study should be replicated with more 
participants in the future and should examine the opinions of parents, teachers, and faculty members in different cultures. Researchers also should investigate effective and efficient ways of training teachers about SS instruction.

In a final concluding thought, it is important to note that it should be a goal for all students with disabilities (including those experiencing ASD) to be educated in least restrictive environment with same-age peers. An additional goal should be that all students with disabilities transition to inclusive settings where they will work and live when they complete school. Including SS that promote independence and reflect the cultural environment in which students live is one way to work toward achieving these goals.

\section{References}

Agran, M., \& Krump, M. (2010). A preliminaryinvestigation of parents' opinions about safety skills instruction: An apparent discrepancy between importance and expectation. Education and Training in Autism and Developmental Disabilities, 45, 303311.

Agran, M., Krump, M., Spooner, F., \& Traice-Lynn, Z. (2012). Asking students about the importance of safety skills instruction: A preliminary analysis of what they think is important. Research and Practice for Persons with Severe Disabilities, 37, 45-52.

Akmanoglu, N., \& Tekin-Iftar, E. (2011). Teaching children with autism how to respond to the lures of strangers. Autism: The International Journal of Research and Practice, 15, 185-203. doi: $10.1177 / 1362361309352180$

American Psychiatric Association. (2013). Diagnostic and statistical manual of mental disorders (5th ed.). American Psychiatric Association.

Bergstrom, R., Najdowski, A. C., \& Tarbox, J. (2012). Teaching children with autism to seek help when lost in public. Journal of Applied Behavior Analysis, 45, 191-195.

Bergstrom, R., Najdowski, A. C., \& Tarbox, J. (2014). A systematic replication of teaching children with autism to respond appropriately to lures from strangers. Journal of Applied Behavior Analysis, $47,861-865$.

Calavari, R. N. S., \& Romanczyk, R. G. (2012). Caregiver perspectives on unintentional injury risk in children with an autism spectrum disorder. Journal of Pediatric Nursing, 27, 632-641.
Chavelle, R. M., Strauss, D. J., \& Picket, J. (2001). Causes of death in autism. Journal of Autism and Developmental Disorders, 31, 569-576.

Christensen, D. L., Baio, J., Braun, K. V., Bilder, D., Charles, J., Costantino, J. N., . . . Yeargin-Allsopp, M. (2016). Prevalence and characteristics of autism spectrum disorder among children aged 8 years - Autism and Developmental Disabilities Monitoring Network, 11 Sites, United States, 2012. MMWR Surveillance Summaries, 65(No. SS3), 1-23. doi: http://dx.doi.org/10.15585/mmwr. ss6503a1

Clees, T. J., \& Gast, D. L. (1994). Social safety skills instruction for individuals with disabilities: A sequential model. Education \& Treatment of Children, 17, 163-185.

Collins, B. C., Wolery, M., \& Gast, D. L. (1991). A survey of safety concerns for students with special needs. Education and Training in Mental Retardation, 26, 305-318.

Collins, B. C., Wolery, M., \& Gast, D. L. (1992). A national survey of safety concerns for students with special needs. Journal of Developmental and Physical Disabilities, 4, 263-276.

Creswell, J. W. (2005). Educational research: Planning, conducting, and evaluating quantitative and qualitative research. Merrill.

Dixon, D., Bergstorm, R., Smith, M. N., \& Tarbox, J. (2010). A review of research on procedures for teaching safety skills to persons with developmental disabilities. Research in Developmental Disabilities, 31, 985-994.

Degirmenci, H. D., \& Tekin-Iftar, E., (2019). Efficacy of social stories and video modelling in teaching safety skills to children with autism. Poster Presented at 13th Association for Behavior Analysis 13th Autism Conference, San Fransisco, CA, ABD

Doyle, B.T., \& Doyle-lland, E. (2004). Autism spectrum disorders from A to Z. Future Horizons.

Ergenekon, Y. (2012). Teaching basic first-aid skills against home accidents to children with autism through video modeling. Educational Sciences, Theory, \& Practice, 12, 2759-2766.

Gunby, K. V., \& Rapp, J. T. (2014). The use of behavioral skills training and in situ feedback to protect children with autism from abduction lures. Journal of Applied Behavior Analysis, 47, 856860. 
Gunby, K. V., Carr, J. E., \& Leblanc, L. A. (2010). Teaching abduction-prevention skills to children with autism. Journal of Applied Behavior Analysis, 43, 107-112.

Harriage, B., Blair, K. C., \& Miltenberger, R. (2016). An evaluation of a parent implemented in situ pedestrian safety skills intervention for individuals with autism. Journal of Autism and Developmental Disorders, 46, 2017-2027.

Hoch, H., Taylor, B. A., \& Rodriguez, A. (2009). Teaching teenagers with autism to answer cell phones and seek assistance when lost. Behavior Analysis in Practice, 2, 14-20.

Istre, G. R., McCoy, M., Carlin, D. K., \& McClain, I. (2002). Residential fire related deaths and injuries among children: Fire play, smoke alarms, and prevention. Injury Prevention, 8, 128-132.

Ivey, J. K. (2004). What do parents expect? A study of likelihood and importance issues for children with autism spectrum disorders. Focus on Autism and Other Developmental Disabilities, 19, 27-33. doi: 10.1177/10883576040190010401

Kenny, M. C., Bennett, K. D., Dougery, J., \& Steele, F. (2013). Teaching general safety and body safety training skills to a Latino preschool male with autism. Journal of Child Family Studies, 22, 10921102.

Kogan, M. D., Blumberg, S. J., Schieve, L. A., Boyle, C. A., Perrin, J. M., \& Ghandour, R. M. (2009). Prevalence of parent-reported diagnosis of autism spectrum disorder among children in the US, 2007. Pediatrics, 124, 1395-1403.

Kurt, O., \& Kutlu, M. (2019). Effectiveness of social stories in teaching abduction-prevention skills to children with autism. Journal of Autism and Developmental Disorders, 49, 1-3807-3818. doi: 10.1007/s10803-019-04096-9

Milli Egitim Bakanligi. (2013). Talim terbiye kurulu baskanligi ozel egitim uygulama merkezi (okulu) birinci ve ikinci kademe egitim programi (otistik cocuklar için) (Cirriculum for children with ASD). Ankara. Retrieved from http://ttkb.meb.gov.tr/ dosyalar/programlar/ilkogretim/otistikcocuklar. pdf.

Miltenberger, R. G., \& Gross, A. C. (2011). Teaching safety skills to children. In W. W Fisher, C. C. Piazza, \& H. S. Roane (Eds.), Handbook of applied behavior analysis (pp. 417-432). NY: The Guildford Press.
Scheuermann, B., \& Webber, J. (2002). Autism: Teaching does make a difference. Wadswoth/Thomson Learning.

Sirin, N., \& Tekin-Iftar, E. (2016). Opinions of parents and teachers about safety skills instruction to children with ASD: A preliminary investigation. Journal of Autism and Developmental Disorders, 46, 2653-2665. doi: 10.1007/s10803-016-2809-2

Summers, J., Tarbox, J., Findel-Pyles, R. S., Wilke, A. E., Bergstrom, R., \& Williams, W. L. (2011). Teaching two household safety skills to children with autism. Research in Autism Spectrum Disorders, 5, 629-632.

Taylor, B. A., Hughes, C. E., Richard, E., Hoch, H., \& Coello, A. R. (2004). Teaching teenagers with autism to seek assistance when lost. Journal of Applied Behavior Analysis, 37, 79-82.

Tekin-Iftar, E., Olcay-Gul, S., Sirin, N., Bilmez, H., Degirmenci, D., \& Collins, B. C. (2021). Systematic analysis of safety skill interventions to individuals with autism spectrum disorder. Journal of Special Education, 54(4), 239-250. DOI: $10.1177 / 0022466920918247$

Volkmar, F. R., \& Wiesner, L. A. (2009). A practical guide to autism: What every parent, family member, and teacher needs to know? Wiley.

Wiseman, K. V., McArdell, L. E., Bottini, S. B., \& Gillis, J. M. (2017). A meta-analysis of safety skill interventions for children, adolescents, and young adults with autism spectrum disorders. Review Journal of Autism and Developmental Disorders, 4, 39-49. Doi: 10.1007/s40489-016-00967 